\title{
Whole-virus Vaccine Development by Continuous Culture on a Complementing Host
}

\author{
Deyu Kong and John Yin*
}

Thayer School of Engineering, Dartmouth College, Hanover, New Hampshire 03755-8000. *Corresponding author (e-mail: jyin@ dartmouth.cdu).

We have evaluated an adaptive strategy for generating whole-virus vaccines using a bacteriophage model. Wildtype phage T7 was cultivated in a two-stage continuous stirred-tank reactor (CSTR) utilizing a recombinant $E$. coli host that constitutively expressed T7 RNA polymerase, an essential enzyme of the early viral metabolism. Over the course of 180 generations a diversity of phage variants emerged, outgrew the wildtype, and were subsequently eclipsed by yet fitter variants, based on host-ranges, restriction patterns, and one-step growth responses of isolated clones. The fittest variant, which required complementation by the recombinant host in order to grow, deleted at least 12 percent of its genome and replicated twice as fast as the wildtype. Moreover, this variant was immunogenically indistinguishable from the wildtype, based on cross-reactivities of antisera raised against both. These results suggest the feasibility of the proposed strategy for the development of safe whole-virus vaccines.

Received 7 February 1995; accepted 27 March 1995.

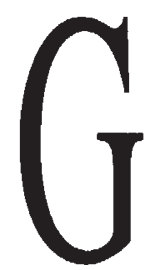
iven the plethora of discoveries from phage research that have been paradigmatic for the development of modern virology, molecular biology, and biotechnology', it is surprising that phage have not in recent years been more widely studied. Research on phage established the respective roles of the virus and host during an infection, showing the role of the virus as an information bearing instructive entity and the host as a replication machine'. The classic 'blender' experiments of Hershey and Chase provided the final proof that DNA, not protein is the genetic material of genes ${ }^{3}$. Moreover, phage research established that the order of amino acids in a protein is a linear mapping of its gene $e^{4}$ and led to the discovery of restriction enzymes, enabling the birth of recombinant DNA and the biotechnology industries.

More recent phage research has played less obvious, but important, roles in defining new paradigms, particularly by clarifying the molecular-level mechanisms that drive the adaptation of viruses. The low fidelity of replication exhibited by the replicase from the single-stranded RNA phage, $Q_{\beta}$, has been found to enable the diversification of phage RNA populations during in vitro ${ }^{6}$ and in vivo $o^{7}$ laboratory passages. These studies inspired the quasi-species model of Eigen and co-workers ${ }^{8-10}$, a

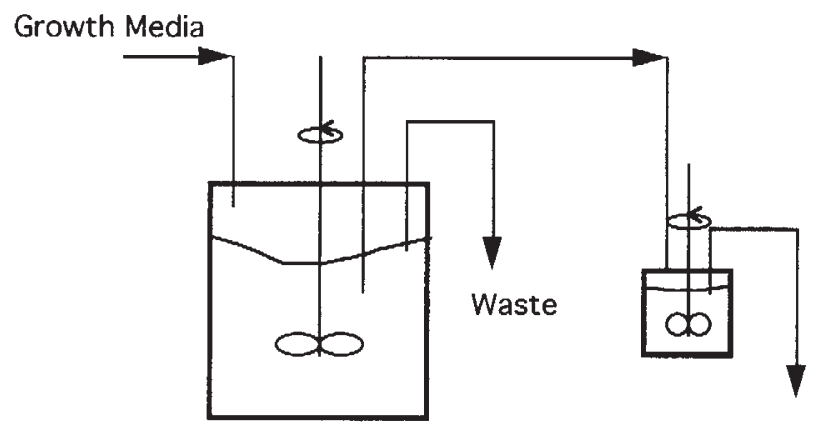

Bacterial Culture Bacteriophage Culture

Figure 1. Two-stage flow reactor for continuous culture of phage. physicochemical model that demonstrates how macromolecular information originates by way of specific, though error-prone, autocatalytic reactions, which give rise to stationary population distributions, termed "quasi-species." Experimental phage work and the Eigen model have established a rigorous framework for understanding the evolution of other viruses. Low fidelities of replication by the replicase of phage $Q_{\beta}$ " foreshadowed, by more than a decade, measurements of low fidelities on the reverse-transcriptase of HIV-1 (ref. 12). Moreover, the heterogeneous nature of virus populations anticipated by the quasi-species model has been verified experimentally in recent years for HIV-1 (ref. 13), influenza $\mathrm{A}^{14}$, foot-and-mouthdisease virus ${ }^{15}$, vesicular stomatitis virus ${ }^{16}$, and others ${ }^{17}$.

Here we propose and test a strategy for vaccine development using phage as a model system. Attenuated 'live' vaccines have traditionally been developed by passage of a virulent virus strain until various ill-defined indicators for non-virulence such as cytopathogenicity, reduced infectivity, syncytium formation, serologic response ${ }^{18}$, plaque $\operatorname{size}^{14}$, or temperature sensitivity ${ }^{20}$ have suggested the suitability of the vaccine for human testing. Since the molecular mechanisms of attenuation for different viral systems are not firmly established ${ }^{21-23}$, we propose a procedure for attenuation and, ultimately, viral inactivation, for which the mechanism is predictable and verifiable. Here, we continuously culture phage T7 on BL21(DE2), a host that constitutively expresses the T7 RNA polymerase, an essential early enzyme ${ }^{24}$; earlier tests of a continuous phage culture in growing plaques showed that phage variants requiring the host-provided polymerase for growth could result ${ }^{25}$. By employing a two-stage continuous-stirred-tank reactor ${ }^{26.27}$ rather than a growing plaque, we were able to continuously fced fresh host to the replicating phage over the course of the experiment.

\section{Results}

Phage culture in a flow-through reactor. The continuous culture of phage requires a constant source of receptive host bacteria. Although phage have traditionally been propagated over multiple generations by serial passage ${ }^{7}$, their continuous propagation can be facilitated by employing a two-stage continuous reactor cascade (Fig. 1), as proposed by Husimi ${ }^{26}$. Here, a continuous culture of host $E$. coli in the first stage constantly supplied fresh host to the second stage for the continuous propagation of phage. The phage concentration in the second stage oscillated immediately following the inoculation of phage (Fig. $2 \mathrm{~A}$, inset) due to the lag-burst nature of the 




Time (hours)

Figure 2. Continuous bacteriophage culture over 40 hours. (A) Maintenance of infectious titer. (B) Emergence of phage mutants. $\triangle$ Total mutant; $\square$ (kin-) mutant; $\bigcirc$ (poly-) mutant.

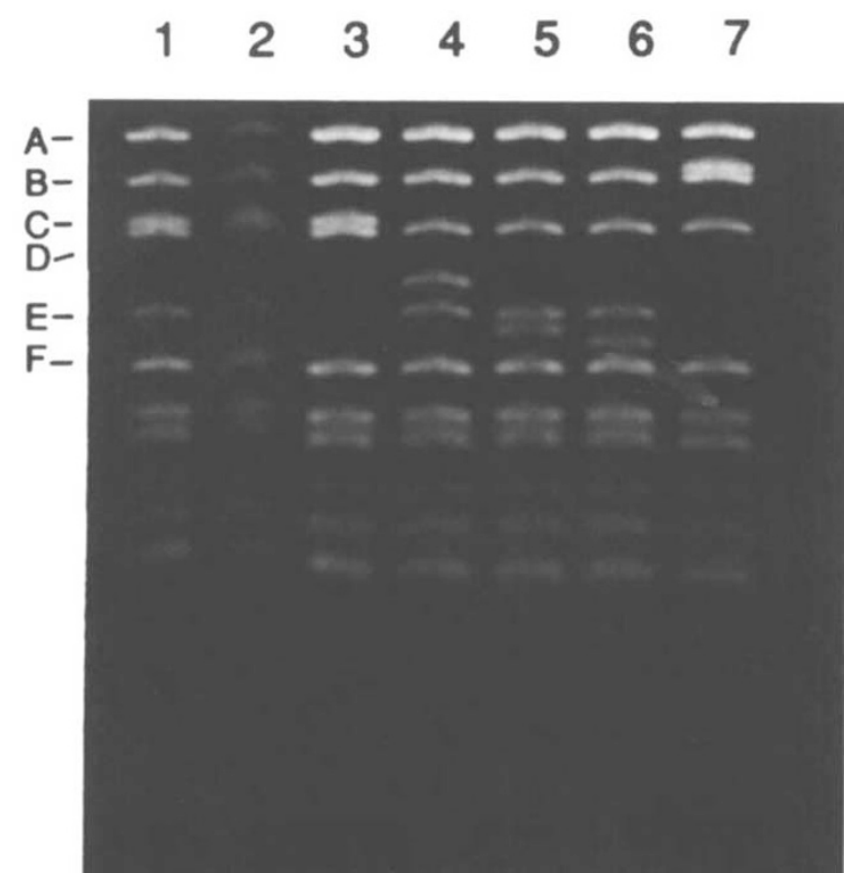

Figure 3. Hae II digestion patterns of emerging phage strains. Detailed descriptions are provided in the text. Lane 1: WT, original phage stock; Lane 2: WT, isolated at $36.4 \mathrm{hr}$; Lane 3: (kin-), 28.4 hr; Lane 4: (poly-), 35.7 hr; Lane 5: (poly-), $39.3 \mathrm{hr}$; Lane 6: (poly-), $43.7 \mathrm{hr}$; Lane 7: (poly-), $43.7 \mathrm{hr}$. phage replication ${ }^{28}$ and the constant dilution experienced by the phage population. The oscillations were damped over the course of several generations, a phenomenon that has been observed $^{29}$. After the initial transients passed, the phage concentration was maintained at about $7 \times 10^{5} \mathrm{PFU} / \mathrm{ml}$ for more than 40 hours (Fig. 2A).

Emergence of phage mutants. After 25 hours, mutant phage appeared and by 36 hours displaced the wildtype (Fig. 2B). Since eleven hours elapsed between the first detection of the mutants and their outgrowth, a lower bound of 44 phage generations were required for displacement of the wildtype, assuming four phage generations per hour. The displacement of the wildtype was accomplished by the interplay of at least two mutants. The first was designated (kin-) because its limited host range suggested that it was kinase defective, and the second was (poly-) because it required host complementation of the T7 RNA polymerase in order to grow. Between 35 and 36 hours, the second mutant was detectable against a population dominated by the (kin-) phenotype, but still containing detectable wildtype.

Genetic characterization of phage mutants. The emergent genealogy was revealed by comparing Hae II restriction patterns of 26 mutants isolated over the course of the selection process, between 28 and 44 hours. The correspondence between restriction fragments and genes is known $n^{30}$. From clones of the 26 isolates, five digestion patterns were found (Fig. 3). Only one digestion pattern corresponded with the (kin-) mutant (Fig. 3, lane 3), whose deletion involved fragment $\mathrm{E}$. The remaining four digestion patterns were (poly-) mutants, deleted in fragment $\mathrm{C}$. Mutant 26 contained the largest deletion, affecting both fragments $\mathrm{C}$ and $\mathrm{E}$ (Fig. 3, lane 7). The size of this deletion was calculated to be at least 12 percent of the wildtype T7 genome. It is evident that a heterogeneous population contributed to the displacement of the wildtype $\mathrm{T} 7$ following the appearance of the initial (kin-) mutant; the patterns suggest that the (poly-) mutants did not descend from the (kin-) mutant, because the early (poly-) mutants contain fragment $\mathrm{E}$, which the (kin-) mutant deleted. The reason for the displacement of the wildtype by the mutants was apparent from one-step growth cultures, where it was found that all the isolated mutants exhibited significantly greater infection yields than wildtype T7 (data not shown). Notably, Mutant 26 produced a two-fold higher yield than wildtype T7. Recent computer simulations of the intracellular kinetics of $\mathrm{T} 7$ replication suggest that the larger burst size can directly be attributed to a shift towards earlier transcription of phage proteins by the deletion mutants, relative to the wildtype (in preparation).

Immunogenicity of phage mutant. Mutant 26 was immunogenically indistinguishable from wildtype $\mathrm{T} 7$, based on titrations of antisera activity (Fig. 4). In the left panel of Figure 4 antiserum raised against wildtype T7 completely neutralized both wildtype T7 and Mutant 26 at a $10^{3}$-fold dilution, but was inactive at a $10^{6}$-fold dilution; at intermediate dilutions the survival fractions of the wildtype and mutant were indistinguishable from each other. Similar results were found for the antiserum raised against Mutant 26 (Fig. 4, right panel). Neutralization curves for phage M13, an unrelated phage serving as a control, were at the background level, as expected. Mutant 26 was unable to infect normal cells, due to a deletion in the gene encoding its RNA polymerase, an essential enzyme of the normal phage replication process. Together, these results indicate that the evolutionary strategy that gave rise to Mutant 26 may be feasible as an approach for the generation of safe intact-virion vaccines.

\section{Discussion}

Our results indicate that trans complementation of an 
Figure 4. Neutralizing curves for antisera against wildtype T7 and Mutant 26. Concentration units are relative to undiluted antisera, and survival fraction refers to the fraction of phage that resist neutralization. Wildtype T7; 1 Mut 26; $\Delta$ Phage M13 (control).
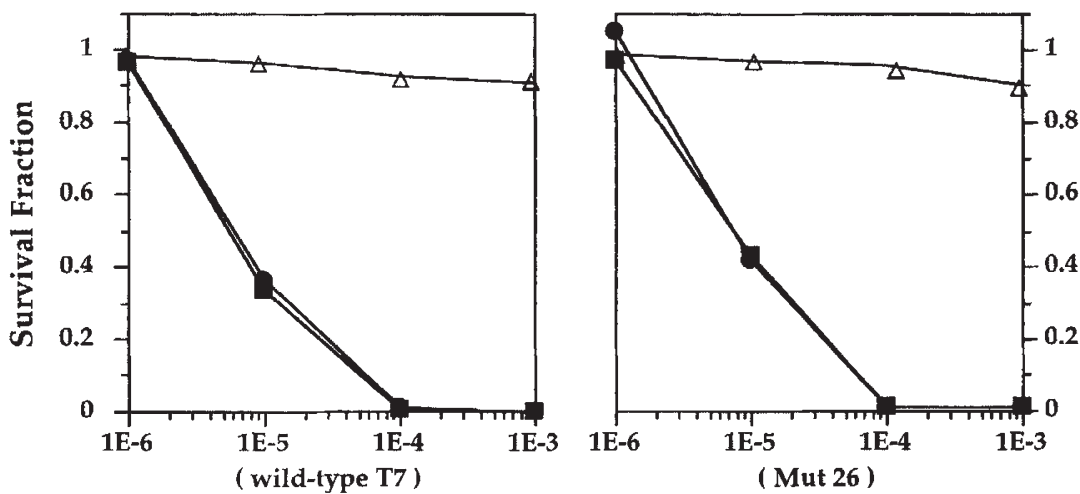

Crude Antiserum Concentration against (Phage) essential viral function, supplied over the course of multiple virus generations, can promote the emergence of mutant viruses, defective in the function. The mutants, which are unable to replicate on natural hosts, are immunogenically indistinguishable from the wildtype virus, suggesting their suitability as safe, whole-virion vaccines.

To date, studies on adenovirus, herpes simplex virus (HSV), and simian immunodeficiency virus (SIV), support the feasibility of the proposed strategy for generating animal vaccines. More than a decade ago, deletion mutants of adenovirus, created using recombinant techniques, were found to be unable to grow on normally susceptible human embryonic kidney cells, yet they readily propagated on the cells transformed by fragments of adenovirus DNA ${ }^{31}$, indicating that the transformed cells were able to complement the deleted function. More recently, an HSV construct containing a deletion in the gene for its essential glycoprotein $\mathrm{H}$ could only be propagated on a cell line that supplied the glycoprotein in $\operatorname{trans}^{32}$. In addition, immunization of mice with this construct made them resistant to challenge with a high dose of wildtype virus ${ }^{33}$. More recent work showing that rhesus monkeys vaccinated with a mutant of SIV lacking a sequence presumably involved in promoting vigorous virus replication in vivo ${ }^{34}$, were protected when challenged by pathogenic SIV ${ }^{35}$.

Although these deletion mutants have already been created using the tools of molecular genetics, the strategy of generating deletion-mutant vaccines by continuous culture or serial passage may offer advantages by enabling the production of heterogeneous vaccines. This is indircctly supported by theoretical and experimental observations. Eigen's quasi-species theory indicates that the target of selection in natural populations of error-prone replicators, such as rapidly evolving viruses, is not a genetically homogeneous species, but a defined distribution of many closely related species ${ }^{8-10}$, the socalled quasi-species ${ }^{36}$. This suggests that an animal's immune response to infection by a natural viral quasi-species may be more effective when primed by a vaccine that anticipates and reflects the heterogeneity of the quasi-species than by one that is genetically pure. It is noteworthy that in the presence of a high-titer of neutralizing monoclonal antibody (MAb), in vitro infection of MT4 cells by a cloned HIV strain selects plaques containing MAb-resistant virus ${ }^{37}$, dcmonstrating the remarkable ability of HIV to mutate and escape a homogeneous antiHIV environment. Finally, we speculate that the success of serial passage in generating effective live-attenuated vaccines against rubella, yellow fever, mumps, polio, measles, and smallpox ${ }^{38}$ can in part be attributed to their heterogeneity and the resultant breadth of their elicited immune responses.

\section{Experimental Protocol}

Phage and host strains. Standard techniques were employed to handle and store bacteria and phage $\mathrm{e}^{28.39-11}$. Bacteriophage T7, and E. coll BL21(DE2), BL21 and BR3, were provided by F.W. Siudier. Strain BI,21(DE2), which was uscd to seed the host reactor, constitutively expresses the T7 RNA polymerase to a level such that T7 delction mutants lacking the RNA polymerasc, indicated here as (poly-), are complemented. Host strains BL2 1(DE2) and BI.21 can support the growth of kinase defeclive (kin-) mutants, but BR3 cannot.

Continuous culture. Two continuous stirred reactors in series were used for phage cultivation, as shown in Figure 1. The first reactor was inoculated with $E$. coli $\mathrm{BL} 21(\mathrm{DE} 2)$ growing on $\mathrm{M} 9$ media. It was first run as a batch culture for 5-7 hours to reach an $O D_{\text {mu }}$ of $(0.1$ and was then switched to continuous culture at 0.05 to $0.08 \mathrm{hr}^{-1}$ difution rate. The bacteria culture was run continuously for at least 12 hours before fecding the second reactor and inoculating with phage. The dilution rate in the phage reactor was typically set in the range 0.5 to $1 \mathrm{hr}^{-1}$

Double-layer plating assay. Three bactcrial host strains, BL21(DE2), BL2 1 and BR3, were used to characterize mutant phages ${ }^{42.43}$. Based on their growth on each of these bacterial strains, threc phenotypes can be identified: Wildtype phage (WT) grows on all strains; kinase-defective mutants (kin-) grow on BL21 and BL21(DE2) but not on BR3; and polymerase defective mutants (poly-), which may also be defective in kinase, grow only on BL21(DE2).

Restriction patterns. Phage DNA was prepared from phage lysates and separated by gel electrophoresis as previously described ${ }^{25}$. Agarose gels at $1 \%$ were loaded and run at $4 \mathrm{~V} / \mathrm{cm}$ for 2 to 5 hours.

Antisera cross-reactivity. After being concentrated by PEG 8000 / $\mathrm{NaCl}$ precipitation, phage stocks of wildtype and Mutant 26 were purified by $\mathrm{CsCl}$ gradient ultracentrifugation and membrane dialysis ${ }^{414}$. Rabbit antisera against the phage were raised by Cocalico Biologicals, Inc. Reamstown, PA. Following an initial inoculation, rabbits were boosted with purified phage stocks on the 14th, 21 st and 49th days. Test antisera were collected on the 35 th and $56 \mathrm{th}$ days. The neutralization activitics of the 56 th day antisera were determined by subjccting phage for three minutes to different dilutions of antisera and measuring phage titers by standard agar-layer plating. The survival fraction, defined as the ratio of final to initial phage titers, was determined for cach antiserum dilution.

\section{Acknowledgments}

We thank F. William Studier and Alvin Converse for helpful suggestions and comments. Financial support was provided by the National Science Foundation (Young Investigator Award and Research Initiation Award to J.Y.) and the Thayer School of Engineering, Dartmouth College.

\section{References}

1. Brock, T. D. 1990. The timergence of Bacterial Genetics. Cold Spring Harbor N.Y., Colk Spring Harbor Laboratory Press.

2. Cohen, S. 1949. Growth requirements of bacterial vinuses. Bact. Rev. 13:1-24

3. Hershey, A. and Chase, M. 1952. Independent functions of viral protein and nucleic acid in growth of bacteriophage. J. Gen. Physiol 36:39-56.

4. Benzer, S. 1961. On the topography of the genetic fine structure. Proc. Natl. Acad. Sci. USA 47:403-415.

5. Arber, W. 1965. Host-controlled modification of bacteriophage. Ann. Rev. Microbiol. 19:365-378.

6. Mills, D., Peterson, R. and Spiegelman, S. 1967. An extracellular Darwinian experiment with a self-duplicating mucleic acid molecule. Proc. Natl. Acad. Sci. USA 58:217-224.

7. Domingo, E., Sabo, D., Taniguchi, T. and Weissmann, C. 1978. Nucleotide sequence heterogeneity of an RNA phage population. Cell 13:735-744.

8. Eigen, M. 1971. Selforganization of matter and the evolution of biological macromolecules. Naturwissenschaften 58:465-523.

9. Eigen, M., McCaskill, J. and Schuster, P. 1988. Molecular quasi-species. J 


\section{BIOTECHNOLOGY RESEARCH PAPERS AUTHOR'S GUIDE}

Bio/Technology publishes applied and basic research papers with implications for biotechnology. The disciplines we cover include molecular biology, microbiology, biochemistry, and plant and animal biology, among others. In order to maintain our policy of rapid publication (usually three to four months after acceptance), we ask that research papers be no more than 3000 words long with a maximum of five illustrations (figures or tables). Bio/Technology also welcomes the submission of shorter, single-topic research notes of no more than 1500 words with a maximum of three illustrations. Only original work will be published in the research section of Bio/Technology; material submitted elsewhere will not be considered.

Three copies of the manuscript, formatted using any of Bio/Technology's previously published papers as a guide and any illustrations should be sent to Bio/Technology's Research Editor. Please include a cover letter describing the originality and potential application(s) of the research. Manuscripts selected for possible publication will undergo peer review by two or more referees. Authors are encouraged to suggest two referees, but the final selection of reviewers is at the discretion of the editors. Bio/Technology customarily publishes papers without paper charges. In the case of papers that exceed our space constraints or contain color illustrations, however, the authors will be asked to help defray the costs.

Research review articles, feature articles, and book reviews are commissioned by the editors; suggestions and proposals are welcome.

For further information: Editorial Offices Bio/Technology, 345 Park Ave. South New York, NY 10010. (212) 726-9200
Phys. Chem. 92:6881-6891.

10. Eigen. M. 1993. Viral quasispecies. Scientific American 269:42-49.

11. Domingo, E.., Flavell, R. A. and Weissmann, C. 1976. In vitro site-directed mutagenesis: Generation and properties of an infectious extracistronic mutant of bacteriophage Q $\beta$. Gene 1:3-25.

12. Ji, J. and Loeb, L. 1992. Fidelity of HIV-I reverse transcriptase copying RNA in vitro. Biochemistry 31:954-958.

13. Goodenow, M., Huet, T., Saurin, W., Kwok. S.. Sninsky, J. and Wain-Hohson. S. 1989. HIV-I isolates are rapidly evolving quasispecies: evidence for viral mixtures and preferred nucleotide substitutions. JAIDS 2:344-352.

14. Rocha, F., Cox, N., Black, R., Hamon, M.. Harrison. C. and Kendal, A. 1991. Antigenic and genetic variation in influensa $\mathrm{A}$ (HINI) virus isolates recovered from a persistently infected immunodeficient child. 3 . Virology 65:2340-2350.

15. Martinez, M. Carrillo, C.. Gonzalez-Candelas, F., Moya, A., Domingo, E. and Sobrino. F. 1991. Fitness alteration of foot-and-mouth disease virus mutants: measurement of adaptability of viral quasispecies. J. Virology 65:3954-3957.

16. Steinhauer, D., de la Torre, J., Meier, E. and Holland, J. 1989. Extreme heterogeneity in populations of vesicular stomatitis virus. I. Virology 63:2072-2080.

17. Holland, J. 1993. Replication error, quasispecies populations, and extreme evolution rates of RNA viruses, p. 203-218. In: Emerging Viruses. (Eds.?). New York, Oxford Univ. Press, Oxford. UK.

18. Buynak, E. and Hilleman, M. 1966. Live attenuated mumps virus vatecine. 1. Vaccine development. Proc. Soc. Exp. Biol. Med. 123:768-775.

19. Sassani, A., Mirchamsy, H.. Shafyi, A., Ahourai, P., Razavi, J., Gholami, M. Mohammadi, A., Ezzi, A., Rahmani, M. Fateh, G and Paravandi, T. 1991. Development of a new live attenuated mumps virus vaccine in human diploid cells. Biologicals: Journal of the International Association of Biological Standardization 19:203-211.

20. Schoepp, R., Beaty, B. and Eckels, K. 1991. Infection of Aedes albopictus and Aedes aegvpti mosquitoes with dengue parent and progeny candidate vaccine viruses: a possible marker of human attenuation. Am. J. Trop. Med. Hyg. 45:202-210.

21. Cohen, J., Rosenblum, B., Feinstone, S., Ticehurst, J. and Purcell, R. 1989 Attenuation and cell culture adaptation of hepatitis A virus (HAV): a genetic analysis with HAV cDNA. J. Virol 63:5364-5370.

22. Kessler, M. and Aloni, Y. 1989. The block to transcription elongation at the SV40 attenuation site is decreased in vitro by oligomers complementary to segments of the attenuator RNA. Gene 84:65-72.

23. Luo, G., Bergmann, M., Garcia-Sastre, A. and Palese, P. 1992. Mechunism of attenuation of a chimeric influenza A/B transfectant virus. J. Virol. 66:4679-4685.

24. Studier, F. W. and Dunn, J. 1. 1983. Organization and expression of bacteriophage T7 DNA. Cold Spring Harbor Symp. Quant. Biol. 47:999-1007.

25. Yin, J. 1993. Evolution of bacteriophage T7 in a growing plaque. J. Bacteriol. $175: 1272-1277$

26. Husimi. Y., Nishigaki, K., Kinoshita, Y. and Tanaka, T. 1982. Cellstat: a continwous culture system of a bacteriophage for the study of the mutation rate and selection process at the DNA level. Rev. Sci. Instruments 53:517-522.

27. Husimi, Y. 1989. Selection and evolution of bacteriophages in cellstat. Adv. Biophys. 25: 1-43.

28. Adarns, M. 1959. Bacteriophages. New York, Interscience Publishers.

29. Biebricher, C. K., Eigen, M., Gardiner, W. C., Husimi, Y., Keweloh, H. C. and Obst, A. 1987. Modeling studies of RNA replication and viral infection, p. 17-38. In: Complex Chemical Reaction Systems. Editors, J. Warnat\% and W. Jager. Springer-Verlag, Berlin

30. Rosenberg, A. II., Simon, M. N., Studier, F. W. and Roberts, R. J. 1979. Survey and mapping of restriction endonuclease clcavage sites in bacteriophage $\mathrm{T} 7$ DNA. J. Mol. Biol. 135:907-915.

31. Jones, N. and Shenk, T. 1979. Isolation of adenovirus type 5 host range deletion mutants defective for transformation of ral embryo cells. Cell 17:683-689

32. Forrester, A., Farrell, H., Wilkinson, G., Kaye, J., Davis-Poynter, N. and Minson, T. 1992. Construction and propertics of a mutant of herpes simplex virus type I with glycoprotein $\mathrm{H}$ coding sequences deleted. I. Virol 66:341-348

33. Farrell, H., McLean, C., Harley, C.. Efstathiou, S., Inglis, S. and Minson, A. 1994. Vaceine potential of a herpes simplex virus type 1 mutant with an essential glycoprotein deleted. J. Virol. 68:927-932.

34. Desrosiers, R. 1992. HIV with multiple gene deletions as a live allenuated vaccine for AIDS. AIDS Research and Human Retroviruses 8:411-421.

35. Daniel, M., Kirchhoff, F., Cxajak, S., Sehgal, P. and Desrosiers. R. 1992. Protective eflects of a live attenuated SIV vaccine with a deletion in the nef gene. Science 258: 1938-1941.

36. Nowak, M. A. 1992. What is a guasispecies? Trends in ticology and Evolution $7: 118-121$

37. McKeating, J., Gow, J., Goudsmit, J., Pearl, L., Mulder, C. and Weiss, R. 1989 Characterization of IIIV-1 neutralicatiom escape mutants. AIDS 3:777-784.

38. Murphy, B. R. and Chanock, R. M. 1990. Immunization against viruses p. 469-5(22. In: Virology. Fditors-in-chief, B. N. Fields and 1). M. Knipe. Raven Press, NY.

39. Studier, F. W. 1969. The genetics and physiology of bacleriophage T7. Virology 39:562-574

40. Miller, I. H. 1972. Experiments in Molecular Genetics. Cold Spring Harbor Cold Spring Harbor Laboratory, NY

41. Yin. J. 1991. A quantifiable phesutype of viral propugation. Biochemical and Bisphysical Research Communications 174:1009-1014.

42. Studier. F. W. 1979. Relationships among different strains of 77 and amone $T 7$ related bacteriophages. Virology 95:70-84

43. Studier, F. W. and Moffatt, B. A. 1986. Use of bacteriophage T7 RNA poly merase to direct selective high-level expression of cloned genes. J. Mol. Biol $189: 113-130$

44. Maniatis, T. 1982. Molecular Cloning: a Laboratory Manual. Cold Spring Harbor. N.Y., Cold Spring Harbor Laboratory, NY. 